\title{
Computasseia: destacando a participação feminina na História da Computação
}

\author{
Karen da Silva Figueiredo, Jean Carlos Oliveira Santos \\ Instituto de Computação - Universidade Federal do Mato Grosso (UFMT) \\ Cuiabá, Mato Grosso, Brasil \\ karen@ic.ufmt.br, jcoliveira93@gmail.com
}

\begin{abstract}
This paper presents a card game for teaching History of Computing at different levels of education. The proposed game includes equanimous content about women's contribution to Computing.
\end{abstract}

Resumo. O presente trabalho apresenta um jogo de cartas para o ensino de História da Computação em diferentes níveis de ensino que inclui de forma equânime conteúdos sobre a contribuição feminina para a Computação.

\section{Introdução}

É fundamental para estudantes de Computação a compreensão não somente dos aspectos técnicos, mas também dos aspectos culturais da sua área (e.g. a História da Computação) para a evolução dos seus estudos acadêmicos [Berry et al. 2011]. Segundo Fonseca Filho (2007), estudar a História da Computação é essencial para conhecer os fundamentos da área, incentivar à educação para o desenvolvimento de qualidade, tornar claros e relacionar os fatos históricos, acompanhar novas tendências e valorizar o potencial humano.

Atualmente, cursos e carreiras em Computação e áreas afins contam com uma baixa participação feminina [Abbate 2012]. Pesquisas, ações afirmativas e outras estratégias vêm sendo empregadas por diversos grupos nacionais e internacionais para atrair mais mulheres para a área. A presença e a obra de várias mulheres na ciência são geralmente pouco reconhecidas e valorizadas, seus nomes e contribuições são frequentemente "apagados" da história da ciência [Oreskes 1996] e com a Computação não é diferente, e.g. as programadoras do ENIAC foram reconhecidas historicamente apenas décadas depois de sua atuação ${ }^{1}$. Desta forma, ao ensinar História da Computação é indispensável que a participação feminina seja incluída, não só pelo respeito à veracidade histórica, mas também como estratégia para a atração de mais mulheres para a Computação. A possibilidade de atração de novos talentos para a Computação através da história é possível pelo fator inspirador que o ensino das histórias dos grandes feitos computacionais e personalidades podem promover [Fonseca Filho 2007].

O objetivo deste trabalho é apresentar um jogo sério para o ensino de História da Computação chamado Computasseia. Computasseia é um jogo de cartas de estratégia elaborado como recurso educacional de apoio ao ensino de História da Computação, pensando na dificuldade encontrada algumas vezes por educadores ao trabalharem de

http://eniacprogrammers.org/ 
forma atrativa para os alunos tais temáticas históricas repletas de nomes, fatos e datas importantes. O jogo entra no processo de ensino-aprendizagem como ferramenta lúdica, auxiliando na aprendizagem e retenção de conteúdos pelos alunos. No Computasseia são apresentados de forma equânime conteúdos sobre a contribuição feminina para a Computação, ressaltando para o jogador informações que muitas vezes são colocadas em segundo plano e mostrando que as mulheres também somam parte importante para a História da Computação.

\section{Computasseia}

O Computasseia [Santos e Figueiredo 2016] é um jogo de cartas de estratégia desenvolvido, prioritariamente, para dar suporte ao ensino da História da Computação em diferentes níveis de ensino (técnico, graduação e pós-graduação). O jogo é atualmente composto por um conjunto de 80 cartas distintas ${ }^{2}$, cada uma representando uma parte significativa da História da Computação. Cada carta do jogo pertence a uma Categoria (Personalidades, Instituições e Eventos) e a uma ou mais Áreas do Conhecimento (Hardware, Software, Gestão de Dados, Teoria Computacional e Matemática e Computação e Sociedade), a fim de melhor organizar os conteúdos e trazer mais um nível de informação ao jogador.

O conjunto de cartas do Computasseia conta com 30 cartas de Personalidades para representar pessoas que contribuíram de forma significativa com teorias, invenções, ideias ou princípios para pelo menos uma das Áreas do Conhecimento. Destas, 15 cartas são sobre personalidades femininas, a citar: Ada Lovelace, Grace Hopper, Hedy Lamarr, Jean Jennings Bartik, Kathleen Booth, Carol Shaw, Susan Kare, Sophie Wilson, Adele Goldberg, Emmy Noether, Marissa Mayer, Ginni Rometty, Margaret Whitman, Shafrira Goldwasser e Anita Borg. Além destas cartas, estão presentes no jogo de forma equânime cartas de Eventos e Instituições que abordam criações femininas e locais em que a atuação feminina foi destaque, e.g. Primeiro Algoritmo Processado por Máquina, Primeiro Compilador, Bletchley Park e The Anita Borg Institute.

As cartas do Computasseia são compostas dos seguintes elementos gráficos que podem ser visualizados na Figura 1: 1) Título - o nome da carta, indicando de forma direta o que a carta representa; 2) Imagem ilustrativa - representação imagética da carta; 3) Área do Conhecimento - a área ou áreas associadas à carta; 4) Categoria - a categoria da carta (Personalidade, Instituição ou Evento); 5) Descrição - descrição textual que introduz o conceito da carta, complementando a informação do título e expandindo sua contextualização histórica e relevância computacional; e 6) Data marco temporal que está associado ao fato histórico que a carta representa.

Todas as cartas e demais informações sobre o jogo Computasseia estão disponíveis no site do jogo ${ }^{3}$.

A dinâmica do jogo Computasseia consiste na elaboração conjunta pelos jogadores de uma Linha do Tempo ${ }^{4}$ de marcos da história da Computação, formada pela

\footnotetext{
2 O conjunto de cartas do jogo pode ser estendido, para incluir novas cartas no futuro, seguindo a padronização do jogo.

http://gameinclass.ic.ufmt.br/computassy/

Dinâmica inspirada no jogo infanto-juvenil Timeline da Galapagos Jogos.
} 
disposição sequencial em ordem crescente da Data das cartas, constituindo uma cronologia. Cada jogador recebe no início do jogo um conjunto de seis cartas atribuídas de forma aleatória. As demais cartas restantes do jogo são empilhadas em um montante denominado Montante de Compra com a visão da frente voltada para cima. O Computasseia comporta de dois a seis jogadores devido à sua quantidade de cartas atual.
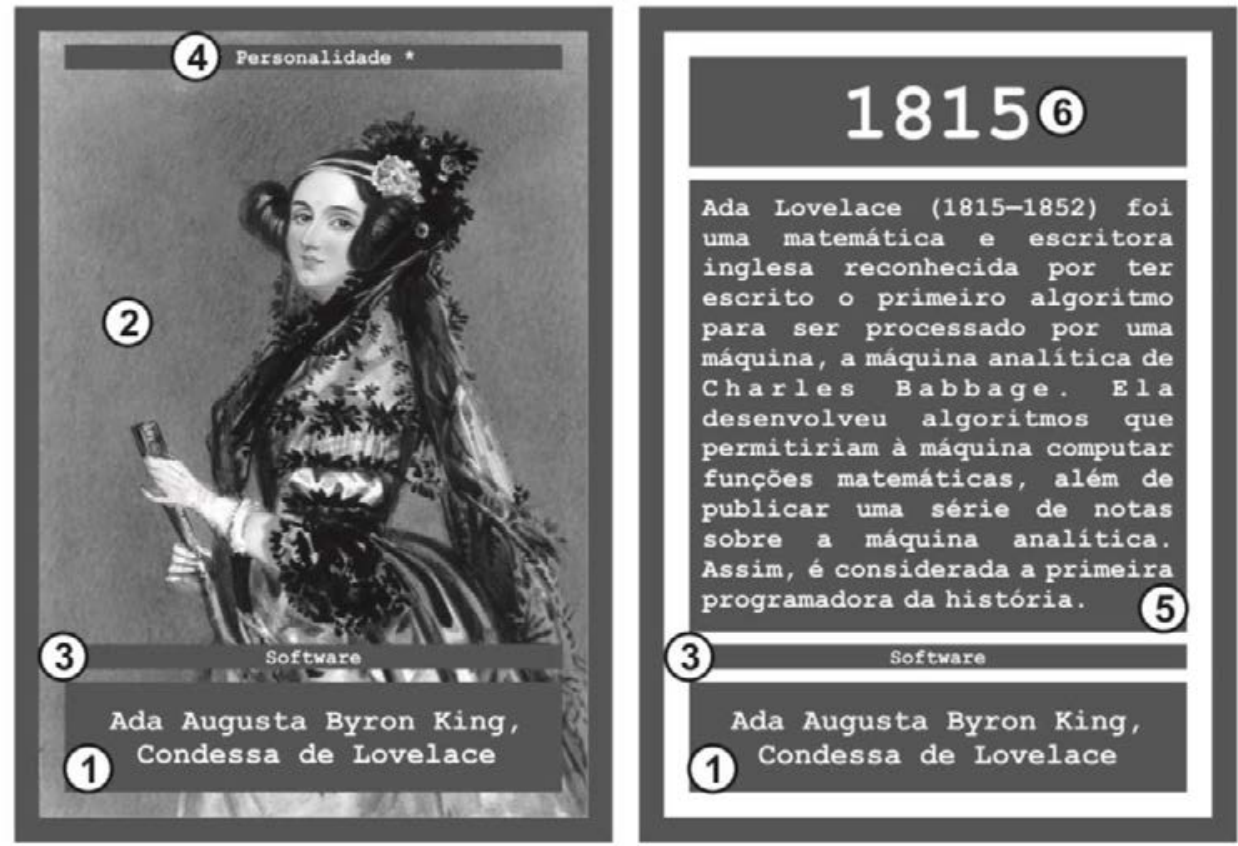

Figura 1. Exemplo de carta de Personalidade feminina do jogo Computasseia e seus elementos indicados

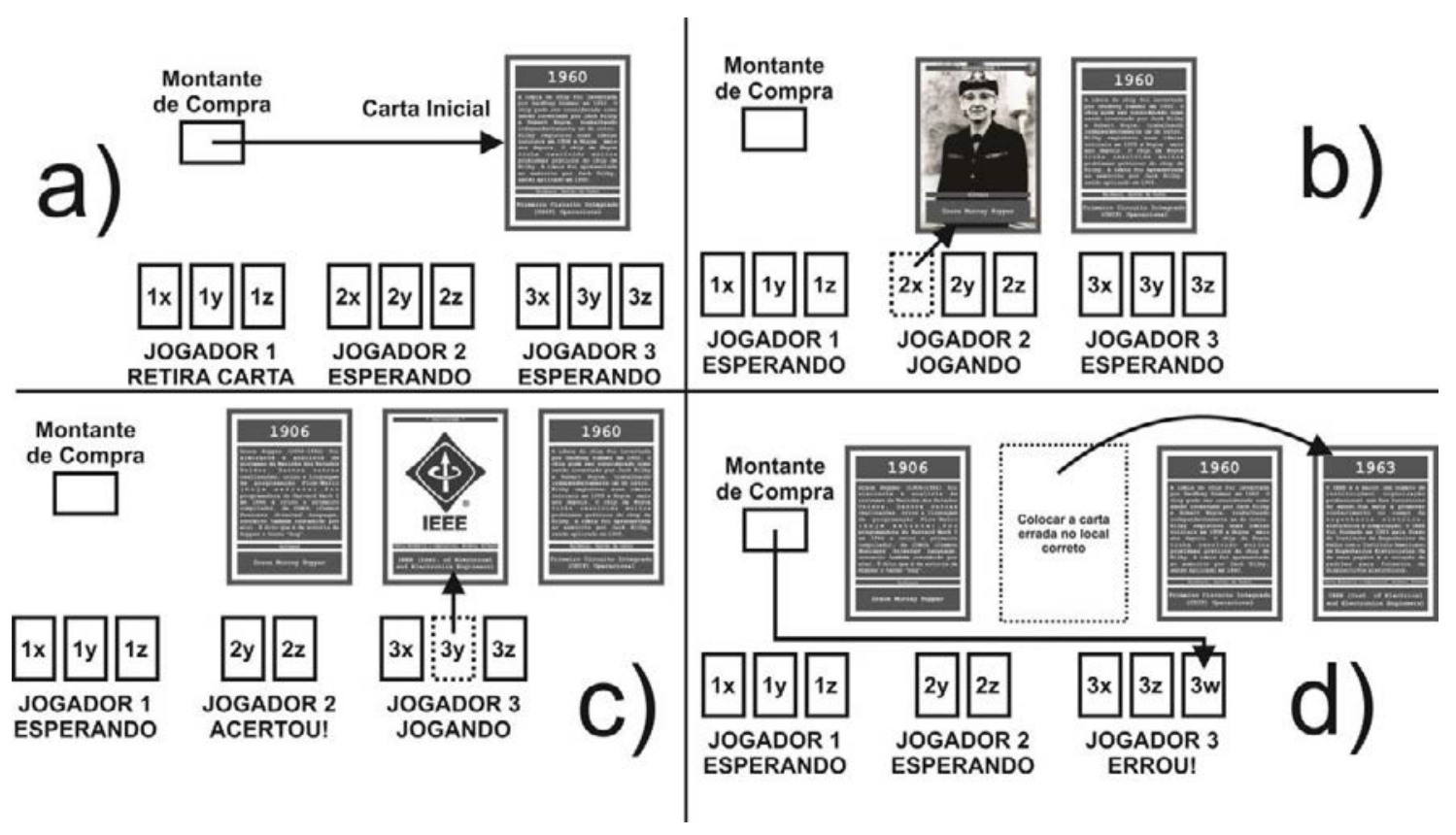

Figura 2. Passos demonstrativos de uma jogada no Computasseia

Ao receber as cartas, o jogador que as recebe deve continuar observando suas cartas apenas a partir da visão frontal das mesmas, sem observar o lado das cartas que 
contém a Data e a Descrição. Os jogadores se posicionam em volta do local em que será montada a Linha do Tempo (ver Figura 2a). Um por um, em sentido escolhido pelos jogadores, o jogador da vez deverá escolher uma das cartas em sua mão para utilizar em sua jogada. Assim que fizer a escolha, deverá tentar inseri-la na posição que julga ser a correta na Linha do Tempo (ver Figura 2b). Feito isto, a face da carta jogada é virada, revelando suas informações de Data e Descrição contidas no verso. Logo, é verificado o acerto ou erro da jogada (ver Figura 2c e d).

Caso o jogador tenha errado a posição da carta, essa carta é mantida na Linha do Tempo, porém a mesma deve ser recolocada na sua posição apropriada e o jogador deve retirar uma nova carta no Montante de Compra para as suas cartas da mão (ver Figura 2d). A vez de jogada é passada ao próximo jogador. O jogo acaba quando um dos jogadores consegue descartar de forma apropriada todas as cartas de sua mão para a Linha do Tempo do jogo, sendo o mesmo declarado vencedor da partida, ou quando o Montante de Compra se esgota - neste caso, o vencedor da partida é o jogador (ou jogadores) com o menor número de cartas em mão. A Figura 2 apresenta passos ilustrativos de uma partida de Computasseia.

\section{Conclusões}

Este trabalho apresentou a versão inicial de um jogo sério de cartas e estratégia para o ensino de História da Computação chamado Computasseia, que aborda fatos importantes de diferentes áreas do conhecimento da Computação, incluindo as contribuições femininas para a História da Computação distribuídas de forma equilibrada no jogo. Os autores do presente trabalho acreditam que o jogo proposto é um recurso acessível aos educadores (podendo ser facilmente impresso no site do jogo e utilizado até de outras maneiras - e.g. estilo "jogo da memória", imprimindo frente e verso como cartas separadas), podendo funcionar como estratégia motivacional para atrair mais mulheres para a área e para que os jogadores em geral conheçam e valorizem a participação feminina na construção do passado, presente e futuro da Computação.

\section{Referências}

Abbate, J. (2012) "Recoding gender: women's changing participation in computing", MIT Press, 264p.

Berry, G., Sheard, J., Quartly, M. (2011) “A Virtual Museum of Computing History: an educational resource bringing the relationship between people and computers to life", In: $13^{\text {th }}$ Australasian Computing Education Conference-Volume 114, Australian Computer Society, Inc., p. 79-86.

Fonseca Filho, C. (2007) "História da computação: O Caminho do Pensamento e da Tecnologia", EDIPUCRS, Porto Alegre, 205 p.

Oreskes, N. (1996) "Objectivity or heroism? On the invisibility of women in science", In: Osiris, 11, p. 87-113.

Santos, J. C. O. e Figueiredo, K. S. (2016) "Computasseia: Um Jogo para o Ensino de História da Computação", In: 24 WEI - Workshop sobre Educação em Computação, XXXVI Congresso da Sociedade Brasileira de Computação, Porto Alegre. 